\title{
FLEXIBLE CARBON FIBRE IN LATE LIGAMENTOUS RECONSTRUCTION FOR INSTABILITY OF THE KNEE
}

\author{
R. L. LEYSHON, G. M. CHANNON, D. H. R. JENKINS, Z. A. RÁLIŠ \\ From Cardiff Royal Infirmary, Cardiff
}

\begin{abstract}
Sixty-three knees with chronic ligamentous instability treated with flexible carbon fibre are reviewed. Assessment was by pre-operative and postoperative grading of function in work and sport, together with a subjective evaluation of the result based on stability. Fifteen knees had collateral repairs, seven had cruciate repairs and 41 had combined collateral and cruciate repairs. Overall, $71 \%$ of knees showed improvement in function and $67 \%$ had good or excellent results subjectively. Clinical examination did not correlate well with the patient's evaluation of the result.

Nineteen unselected cases with intra-articular (cruciate) carbon fibre had arthroscopies. Infiltration of collagen tissues into the cruciate replacement was a slower process than at the extra-articular (collateral) site. There was no clinical or macroscopic evidence of synovitis but microscopically there was evidence of synovial irritation.
\end{abstract}

Previous experimental work at Cardiff Royal Infirmary has shown that implants of flexible carbon fibre may develop into satisfactory substitutes for tendons (Jenkins et al. 1977) and ligaments (Jenkins 1978).

These implants are well tolerated by the body in respect of the foreign body response and their success depends on infiltration by new collagen tissue. The flexible carbon acts as an agent to induce the formation of a living substitute for the original structure (Forster $e t$ al. 1978). This has an advantage over other prosthetic replacements since the new implant has the power to adapt physiologically to its new role and to grow stronger rather than weaker with age.

Long-term animal studies using carbon fibre implants have not revealed any adverse tissue reactions (Tayton, Phillips and Ráliš 1982). A preliminary report on the role of flexible carbon fibre implants as tendon and ligament substitutes at various sites in clinical practice gave encouraging results (Jenkins and McKibbin 1980). It is the purpose of this present paper to give a more detailed analysis of the use of flexible carbon fibre in late ligamentous reconstruction for instability of the knee.

R. L. Leyshon, BSc, FRCS, Senior Lecturer

D. H. R. Jenkins, ChM. FRCS Ed, Consultant Orthopaedic Surgeon

Z. A. Ráliš, MD. FCCS. Senior Lecturer

Department of Traumatic and Orthopaedic Surgery, Cardiff Royal Infirmary, Newport Road. Cardiff CF2 ISZ, Wales.

G. M. Channon, FRCS Ed, Consultant Orthopaedic Surgeon

Wycombe General Hospital. Queen Alexandra Road. High Wycombe, Buckinghamshire HP11 2TT. England.

Requests for reprints should be sent to Mr R. L. Leyshon.

(C) 1984 British Editorial Society of Bone and Joint Surgery $0301-620 \times / 84 / 2048 \$ 2.00$

\section{CLINICAL MATERIAL AND METHOD}

From 1976 to 1981 flexible carbon fibre has been used for the late reconstruction of damaged ligaments in 63 knees (62 patients). These patients were re-examined between 12 and 48 months after their operations.

Fifty-four men and eight women (one of whom had both knees operated upon) were reviewed clinically and radiologically. Their occupations and sporting abilities were noted. A careful history was taken of the mode of injury, and the time between injury and the final carbon replacement was noted. Other surgical procedures had in many cases been carried out and these also were recorded.

Table I. Grading of function

\begin{tabular}{|ll|}
\hline Grade & Function \\
\hline 0 & Normal knee \\
1 & Cannot play football or equivalent sport \\
2 & Cannot play squash. tennis or equivalent sport \\
3 & Cannot run \\
4 & Knee gives way on walking \\
\hline
\end{tabular}

After Ireland and Trickey (1980)

The pre-operative record included the symptoms, the functional activity of the knee, which was graded using the criteria in Table I (after Ireland and Trickey 1980 ) and the results of clinical examination. These were available from the notes, as were the operative findings, and a description of the repair used. The postoperative record included the complications, the time in a cast, whether physiotherapy was used, and the length of time required before returning to jogging, running, work and 
sport. Function was graded in the same way as before operation and the patient was asked to give a subjective assessment of the results (Table II). Postoperative symptoms were noted, a full clinical examination carried out and standard radiographs taken.

Table II. Subjective assessment of results

\begin{tabular}{|ll|}
\hline Assessment & Result \\
\hline Fxcellent & $\begin{array}{l}\text { Patient satisfied, no instability, active in original } \\
\text { sport work }\end{array}$ \\
Food & $\begin{array}{l}\text { As above, hut some apprehension during sport } \\
\text { work }\end{array}$ \\
Poor & $\begin{array}{l}\text { Worthwhile improvement, some persistent } \\
\text { instability }\end{array}$ \\
\hline
\end{tabular}

Arthroscopy was performed in an unselected group of 19 patients in whom intra-articular carbon fibre had been used to replace the cruciate ligament; this was done in order to investigate the tissue reaction of carbon fibre placed inside the knee. A 30-degree arthroscope was introduced by the standard anterolateral approach. The tissue which had formed around the carbon prosthesis was inspected and biopsy samples of reconstituted ligament and synovium were taken and examined histologically.

Carbon fibre. All repairs were carried out using quadruple strands of Courtaulds AS Grafil (10000 units per strand), with an electrolytically treated surface.

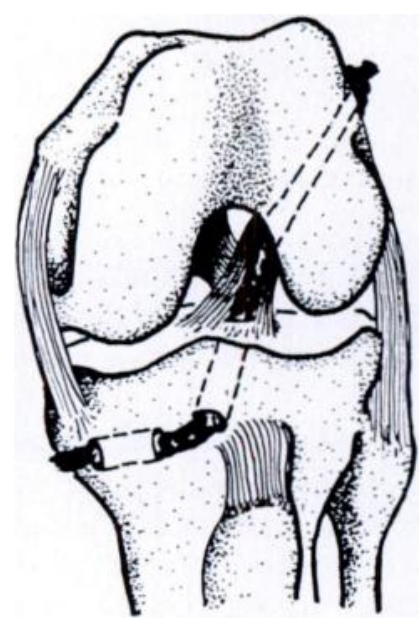

Fig. I

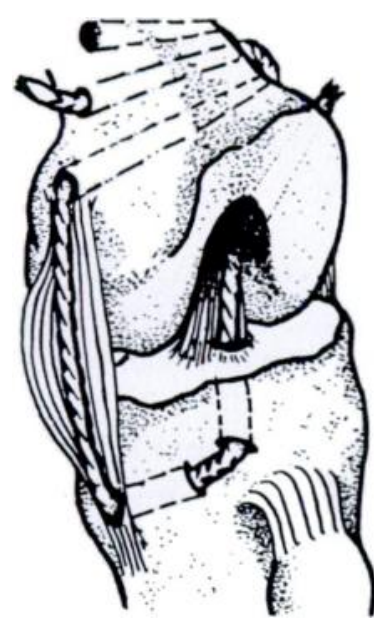

Fig. 2
Figure 1 Flexible carbon fibre used to replace the anterior cruciate ligament. Figure 2 Flexible carbon fibre used to replace the anterior cruciate and the medial collateral ligaments.

Surgical technique. All operations were carried out under tourniquet, using a standard method (Jenkins 1982).

In collateral replacements arthrotomy was not performed. Limited incisions were made at the site of ligamentous attachment to the femur and a hole oneeighth of an inch $(3 \mathrm{~mm})$ in diameter drilled through the bone. The carbon fibre was then passed through the hole using a wire loop, and anchored at the first bone surface by means of a knot which was countersunk. The emerging carbon fibre was then passed in the line of the damaged ligament to a second drill hole in the tibia. The fibre was passed through this hole to emerge on the opposite side. Anchoring the end of the carbon strand was done initially by sewing it to the available soft tissue or periosteum once satisfactory tension had been obtained. In later cases fixation was achieved by the friction generated in a tight tunnel, the carbon being passed back through a second drill hole.

In the replacement of cruciate ligaments, a medial arthrotomy has always been used. For anterior cruciate repairs a drill hole is made far back in the intercondylar notch of the femur on the lateral side. The carbon fibre is then fed down from above and into the knee joint. A second hole is then made to emerge on the spine of the tibia at the site of the original cruciate attachment. After the carbon fibre has been brought through this channel, fixation as previously described can be carried out. If collateral repair is also to be included, then the carbon fibre is fed on through transverse holes as described previously (Figs 1 and 2).

Postoperative management. The repair is protected by a plaster cast for six weeks after operation, though the patient is allowed to bear weight when comfortable. At the end of this period the cast is removed and the patient allowed to mobilise the knee. Formal physiotherapy is no longer instituted routinely, though it was initially. The patient is encouraged to increase the range of movement steadily, without at any time forcing the joint; jogging is allowed at three to four months and at six months the patient may increase his activity up to full running and cutting. Squatting manoeuvres are discouraged as they may result in rupture of the ligament if attempted in the early phases of rehabilitation.

\section{RESULTS}

Fifty-four men and eight women were reviewed. Their ages ranged from 17 to 59 years with an average of 33 years. The majority of injuries (39) occurred during sporting activity, but 8 were industrial, and 11 the result of road traffic accidents. The remainder had an assortment of causes. Many of the patients studied had undergone previous operations on the knee, before the implantation of carbon fibre. Of the entire group, 29 patients had had previous meniscectomies and seven had had unsuccessful ligament reconstructions by other techniques.

The period of time between the original injury and the carbon fibre insertion ranged from 5 months to 15 years with an average of 4 years. The results have been divided into different groups according to the type of replacement performed.

Anterior cruciate replacement alone. Seven of these were reviewed. The subjective results were two excellent, three good and two fair. Two patients showed improved 
function and five remained unchanged. These patients returned to jogging at $3 \frac{1}{2}$ months and running at $4 \frac{1}{2}$ months. The average time off work was two months from the date of operation. The final results showed a loss of flexion of between $5^{\circ}$ and $30^{\circ}$ with a mean of $17^{\circ}$. One patient lost $5^{\circ}$ of extension. All the patients graded good or excellent showed an increase in the amount of anterior drawer compared with the normal side and those patients graded fair were no different on clinical examination from the good or excellent group.

Collateral replacement alone. There were 15 knees in this group. Medial collateral replacement was carried out in six knees, lateral in three, and both medial and lateral on six occasions. Meniscectomy was carried out in two cases at the same operation so that in these formal arthrotomy was required. The subjective results were three excellent, seven good, four fair and one poor. There was improvement in function in 13 knees, one was unchanged and one worse. The mean time to jogging in this group was $5 \frac{1}{2}$ months and to running $6 \frac{1}{2}$ months. The time off work was an average of four months from operation. Loss of movement ranged from $0^{\circ}$ to $60^{\circ}$ with an average of $30^{\circ}$; no patient lost extension. Examination findings were again surprising in this group. In those patients graded good or excellent subjectively, only one had a completely stable knee directly comparable with the uninjured side. The rest all showed varying amounts of laxity. All the knees graded fair subjectively felt just as stable on examination as those in the good or excellent group. The poor result was clinically very unstable.

Combined cruciate and collateral replacements. There were $41 \mathrm{knees}$ in this mixed group and previous operations were common. Thirty-five knees had medial collateral repairs and 21 had lateral collateral repairs. Posterior cruciate replacement was performed on nine occasions and the anterior cruciate was replaced in 34 knees.

Subjectively six of these knees were graded excellent, 21 good, 10 fair and four poor. Postoperatively, 30 knees showed improvement in function, nine were unchanged and two were worse (one went on to arthrodesis and the second has recently had a knee replacement). These patients took longer to regain their mobility, jogging taking an average of six months, running eight months, and return to full sport one year. Three knees showed a final extension lag. The average loss of flexion was $26^{\circ}$ with a range of $0^{\circ}$ to $60^{\circ}$. The results of clinical examination in this group again showed poor correlation with the subjective result. Again excellent and good knees were indistinguishable from fair on examination. The poor knees, however, remained extremely unstable.

Postoperative symptoms were analysed for all groups together. The common complaints were of swelling, stiffness and pain. Eighteen patients complained of swelling in the knee. This was of variable amount and was often related to the amount of exercise done by the patient: it was never large and never troublesome. Stiffness was complained of by 31 patients. This was of two types: firstly, that associated with considerable restriction of movement; and secondly, transient stiffness after resting, which passed off after starting to walk and was not a severe problem. Pain was present in 15 cases. In all but two this was mild, aching in character and present at the end of the day, usually related to exertion. In both the patients in whom it was a problem there were pre-existing degenerative changes in the knees; these knees had poor results and required further operations.

Tattooing of the skin in relation to the implant was seen in 11 patients but this was only of a significant degree in two. Radiography revealed increased lucency at the site of carbon implantation in only one patient; this patient had a poor final result with degenerative changes in the knee. Synovial thickening did not occur in any of the knees examined.

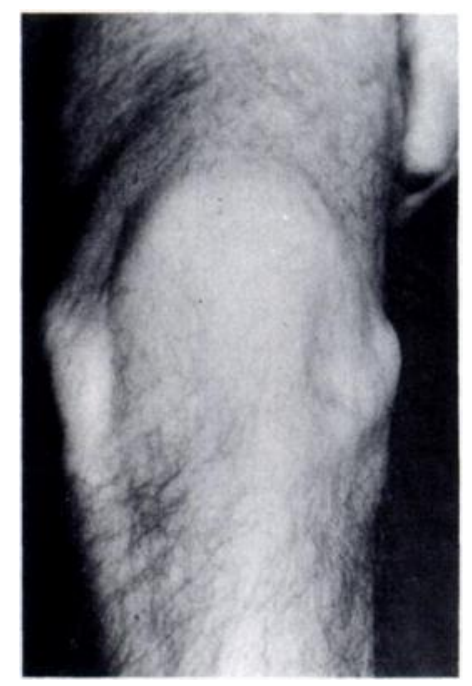

Fig. 3

Hypertrophied carbon fibre collateral reconstructions two years after operation.

At review, the collateral reconstructions could consistently be felt as thick bands at the sides of the knee, due to ingrowth of collagen tissue into the carbon matrix (Fig. 3).

At arthroscopy the appearance of the implanted cruciate carbon fibre was variable. In all patients there was ingrowth of tissue from the tibial attachment. In eight patients there appeared to be good infiltration of the carbon fibre with collagen tissue throughout the length of the implant, but on peeling away the superficial layer bare carbon lay beneath. In the remaining 11 patients there was ingrowth of white tissue along the carbon implant from the tibial attachment but the mid-portion of the implant was bare carbon. Histological samples stained with haematoxylin and eosin showed that the response to the implanted carbon was variable. In a minority of cases, carbon fibres were spread apart by a large amount of collagen tissue (Fig. 4; Stage $C$ of the tissue reaction described in previous studies by Forster et al. 1978) and in these cases the formation of a 


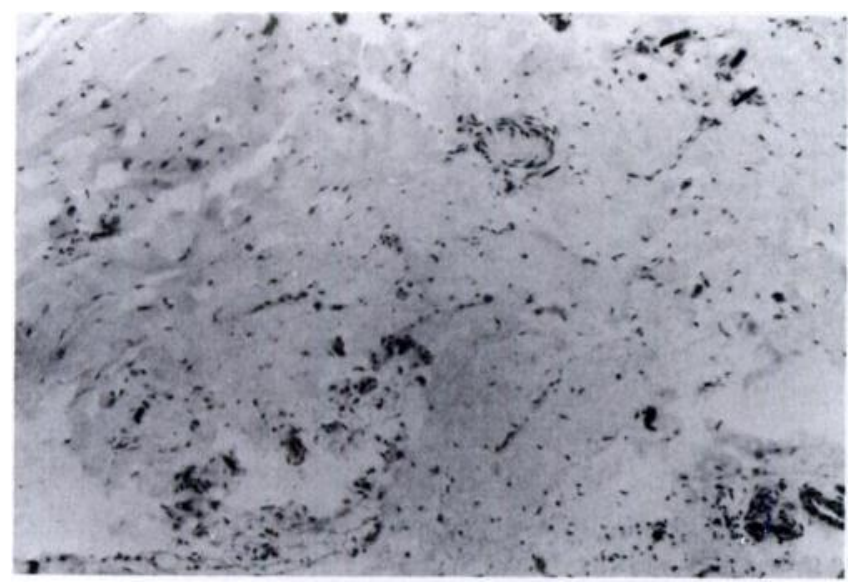

Fig. 4

Carbon fibres widely separated by collagen tissue in an anterior cruciate replacement (haematoxylin and eosin, $\times 40$ ).

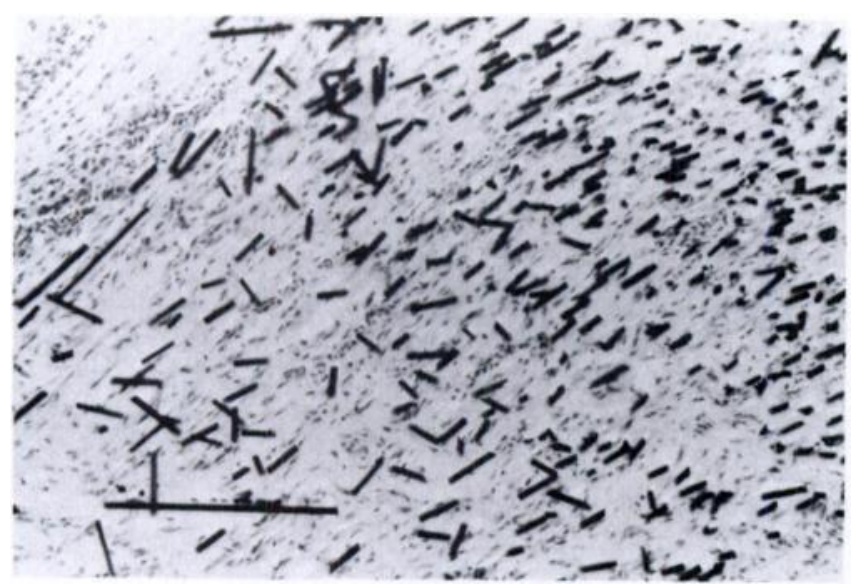

Fig. 5

Poor infiltration of carbon fibre by collagen tissue in an anterior cruciate replacement (haematoxylin and eosin, $\times 40$ ).

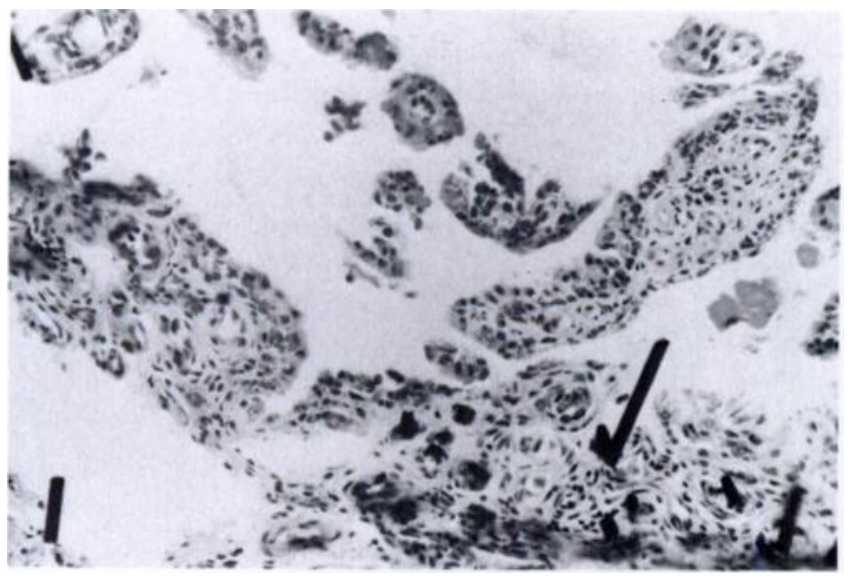

Fig. 6

Synovial biopsy after intra-articular implantation of carbon fibre showing synovial irritation with carbon particles, necrosis of superficial synovial cells, ingrowth of granulation tissue and infiltration of small round cells (haematoxylin and eosin, $\times 40$ ). "neoligament" can be expected to take place. In most cases, however, there was poor infiltration of carbon by collagen tissue and variable amounts of granulation tissue were present (Fig. 5) with poor separation of the carbon rods. The intra-articular response to implanted carbon appears to be a slower and less predictable process than at the extra-articular collateral site.

In all cases, the synovial membrane was yellow in colour and speckled with carbon. The amount of carbon speckling was variable. There was no evidence of macroscopic synovitis but at the microscopic level there was evidence of synovial irritation with necrosis of superficial synovial cells, ingrowth of granulation tissue and infiltration of small round cells (Fig. 6).

\section{DISCUSSION}

Instability of the knee resulting from ligamentous injury gives rise to a complex clinical problem. Many procedures to improve stability have been described. In a "plea for plain words" the type of ligament repair has been classified into reattachment, reinforcement and replacement (Apley 1980). Reattachment in this context implies tightening the stretched capsule and ligaments by advancement of loose structures as ad vocated by Nicholas (1973) and O'Donoghue (1973). Reinforcement of unstable ligaments usually involves tendon transfer and is of two types, dynamic and static. The pes anserinus transfer is a dynamic reinforcement (Slocum and Larson 1968) while the MacIntosh tendonesis for anterolateral instability is a static reconstruction.

Ligament replacement by various structures has been used for many years. Ruptured anterior cruciate ligaments have been replaced by several structures including fascia lata (Hey Groves 1917, 1920; Campbell 1939), the iliotibial band (O'Donoghue 1963) and the central one-third of the patellar ligament (Jones 1963; Lam 1968). The use of carbon fibre as a ligament replacement is a recent concept, and carbon has been used to replace both cruciate and collateral ligaments. In the present series of 63 knees, excellent or good results were achieved in $67 \%$ of cases and function was improved in $71 \%$. As with other methods of ligamentous reconstruction there was a frequent lack of correlation between subjective instability and objective physical signs; this is difficult to explain. In the present series combined collateral-cruciate repairs and collateral repairs gave better functional improvement than anterior cruciate repairs alone, although subjectively there was no difference between the three groups.

The collateral replacements could be felt as thick bands and this clinical finding confirms previous experimental work that the collateral carbon replacement in an extra-articular site becomes infiltrated with collagen tissue which takes over the role of a new ligament. For this to occur it is essential that in the vicinity of the implant there is an adequate pool of mesenchymal tissue, which is a necessary base for production of fibroblastic 
material. Such mesenchymal tissue is present at the extraarticular site, but at the intra-articular site for cruciate replacement its presence is less certain. It has been previously reported that the tissue reaction to carbon fibre implanted into different tissues varies, depending on the character of each implantation site (Ráliš and Forster 1981). Arthroscopy and histological examination of biopsy specimens indeed showed that infiltration of collagen tissue into carbon fibre placed in an intraarticular site is a slower and less predictable process than at extra-articular sites.

The clinical results indicate that the use of carbon fibre for ligament reconstruction is a satisfactory procedure for treating instability of the knee. Collateral ligament reconstruction gave particularly encouraging results with no complications, no long-term weakening of the ligament and no evidence of slipping of the carbon fibre in its bone-tunnel anchorage. The role of carbon fibre to replace cruciate ligaments is less predictable. There was no evidence of clinical or macroscopic synovitis in our series although this has been recently described (Rushton, Dandy and Naylor 1983). However, in view of the microscopic synovial irritation which has occurred, the use of carbon fibre to replace the cruciate ligament should be reserved for those extremely unstable knees with multiple ligamentous laxity. In this type of knee combined collateral and cruciate replacement is valuable in improving knee stability.

\section{REFERENCES}

Apley AG. Instability of the knee resulting from ligamentous injury. A plea for plain words. J Bone Joint Surg [Br] 1980;62-B:515-6.

Campbell WC. Reconstruction of the ligaments of the knee. Am J Surg 1939:43:473-80.

Forster IW, Ráliš ZA, McKibbin B, Jenkins DHR. Biological reaction to carbon fibre implants: the formation and structure of a carbon induced "neotendon". Clin Orthop 1978:131:299-307.

Groves EW Hey. Operation for repair of the crucial ligaments. Lancet 1917:ii:674-5.

Groves EW Hey. The crucial ligaments of the knee joint: their function, rupture and the operative treatment for the same. Br J Surg 1920:7: $505 \cdots 15$.

Ireland J, Trickey EL. MacIntosh tendonesis for anterolateral instability of the knee. J Bone Joint Surg [ Br] 1980:62-B:340-5.

Jenkins DHR, Forster IW, McKibbin B, Ráliš ZA. Induction of tendon and ligament formation by carbon implants. J Bone Joint Surg [Br] 1977:59-B:53-7.

Jenkins DHR. The repair of the cruciate ligaments with flexible carbon fibre : a longer term study of the induction of new ligaments and of the fate of the implanted carbon. J Bone Joint Surg [Br] 1978:60-B:520-2.

Jenkins DHR. The implantation of the Jenkins ligament. Technique manual. Johnson \& Johnson Orthopaedic Division 1982: Volume 1.

Jenkins DHR, McKibbin B. The role of flexible carbon-fibre implants as tendon and ligament substitutes in clinical practice : a preliminary report. J Bone Joint Surg [Br] 1980:62-B:497-9.

Jones KG. Reconstruction of the anterior cruciate ligament: a technique using the central one-third of the patellar ligament. J Bone Joint Surg $[\mathrm{Am}] 1963: 45-\mathrm{A}: 925-32$.

Lam SJS. Reconstruction of the anterior cruciate ligament using the Jones procedure and its Guy`s Hospital modification. J Bone Joint Surg [Am] 1968:50-A:1213-24.

Nicholas JA. The Five-One reconstruction for anteromedial instability of the knee: indications, techniques and results in fifty-two patients. $J$ Bone Joint Surg [Am] 1973:55-A:899-922.

O'Donoghue DH. A method of replacement of the anterior cruciate ligament of the knee: report of twenty cases. J Bome Joimt Surg [Am] 1963: 45-A: $905-24$.

O'Donoghue DH. Reconstruction for medial instability of the knee: technique and results in sixty cases. J Bone Joint Surg [Am] 1973:55-A : 94155.

Ráliš ZA, Forster IW. Choice of the implantation site and other factors influencing the carbon fibre-tissue reaction. J Bone Joint Surg [Br] $1981: 63-B: 295-6$.

Rushton N, Dandy DJ, Naylor CPE. The clinical, arthroscopic and histological findings after replacement of the anterior cruciate ligament with carbon-fibre. J Bone Joint Surg [Br] 1983;65-B:308-9.

Slocum DB, Larson RL. Pes anserinus transplantation : a surgical procedure for control of rotatory instability of the knee. J Bone Joint Surg [Am] 1968:50-A:226-42.

Tayton K, Phillips G, Ráliš ZA. Long-term effects of carbon fibre on soft tissues. J Bone Joint Surg [Br] 1982:64-B: 112-4. 